\title{
A report on primary tuberculosis of glans penis - rare presentation of a common disease
}

\author{
Suchana Marahatta', Sudha Agrawal', Poonam Paudyal ${ }^{2}$ \\ ${ }^{1}$ Department of Dermatology \& Venereology, B. P. Koirala Institute of Health Sciences, Dharan, Nepal, ${ }^{2}$ Department of \\ Pathology, B. P. Koirala Institute of Health Sciences, Dharan, Nepal
}

Corresponding author: Dr. Suchana Marahatta, E-mail: suchanamarahatta@yahoo.com

\begin{abstract}
Penile tuberculosis is an extremely rare form of genitourinary tract tuberculosis even in developing countries with higher tuberculosis prevalence. A 38-year-old married male without promiscuous behavior presented to dermatology outpatient department with a single, painful penile ulcer of $1.5 \times 1 \mathrm{~cm}$ size for last 2 years; which got mildly improved after on and off treatment from local practitioner, but without complete resolution. All workup in the line of sexually transmitted diseases were negative. Incisional biopsy revealed diffuse granuloma, however stain for AFB (TB) was negative. He also had positive mantoux test and raised ESR. On these bases, we started him on category I-anti tuberculosis therapy; which resulted into complete resolution of ulcer leaving behind fibrotic scar. Hence, in country like Nepal where the prevalence of tuberculosis is high, we should always suspect tuberculosis in case of non-healing chronic ulcers.
\end{abstract}

Key words: Chronic Ulcer; Genital tuberculosis; Glans penis

\section{INTRODUCTION}

Penile tuberculosis (TB) is an extremely rare form of genitourinary tract tuberculosis even in developing countries with higher tuberculosis prevalence. Here we are going to present a report on primary tuberculosis of glans penis for its rarity.

\section{CASE REPORT}

A 38-year-old married male presented to dermatology outpatient department with a painful penile ulcer for last 2 years; which got mildly improved after taking treatment from local practitioner, but without complete resolution. He didn't give history of promiscuous behavior. He was heterosexual and his wife did not have any genital problems. Local examination revealed single, $1.5 \times 1 \mathrm{~cm}$, tender ulcer over glans penis with indurated, mildly fibrotic base (Fig. 1). There was no regional lymphadenopathy. All the investigations in the line of sexually transmitted diseases were negative. On laboratory investigation, he had raised $\operatorname{ESR}(35 \mathrm{~mm} / \mathrm{h})$, peripheral lymphocytosis and positive mantoux test (16 mm induration). Incisional tissue biopsy from the margin of ulcer showed diffuse granuloma composed of mixed inflammatory infiltrates, epithelioid cells and langhans giant cells, however stain for AFB (TB) was negative (Fig. 2). However, we could not find focus of tuberculosis in any other organs on thorough workup. After evaluation, we started patient on category I-anti tuberculosis therapy (ATT); which resulted into complete resolution of ulcer leaving behind fibrotic scar (Fig. 3). He does not have recurrence of the lesion till date (three years after completion of ATT) on telephonic follow up.

\section{DISCUSSION}

Though tuberculosis (TB) is one of the commonest infectious diseases in Nepal, frequently affected primary sites are lung and lymph nodes. Primary tuberculosis of the glans penis is extremely rare. Though it was little bit

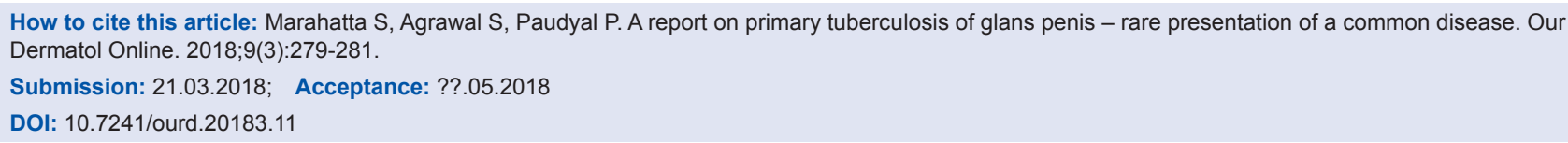




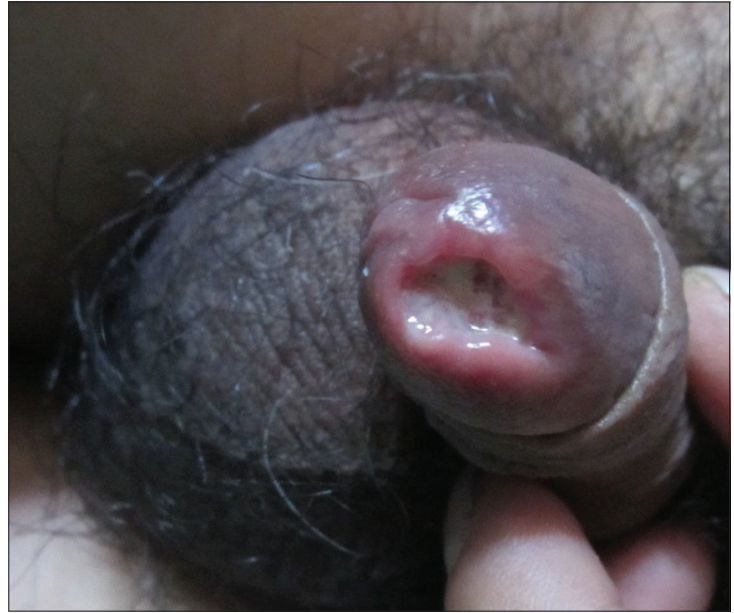

Figure 1: Ulcer over glans penis

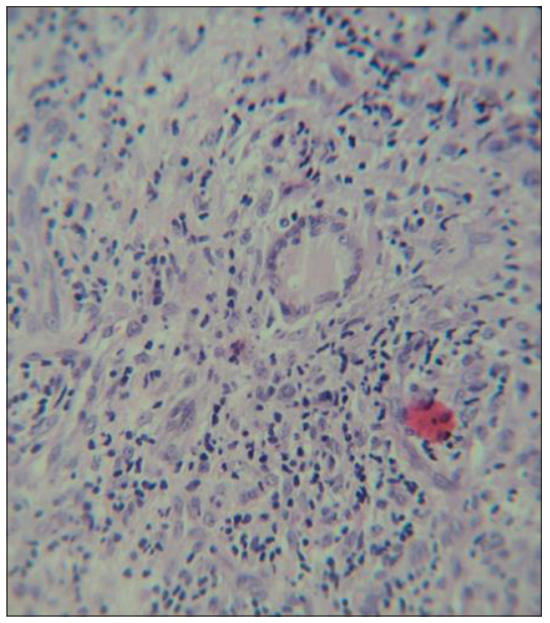

Figure 2: Granuloma comprising of mixed inflammatory infiltrates and multi-nucleated giant cell. H\&E (40X)

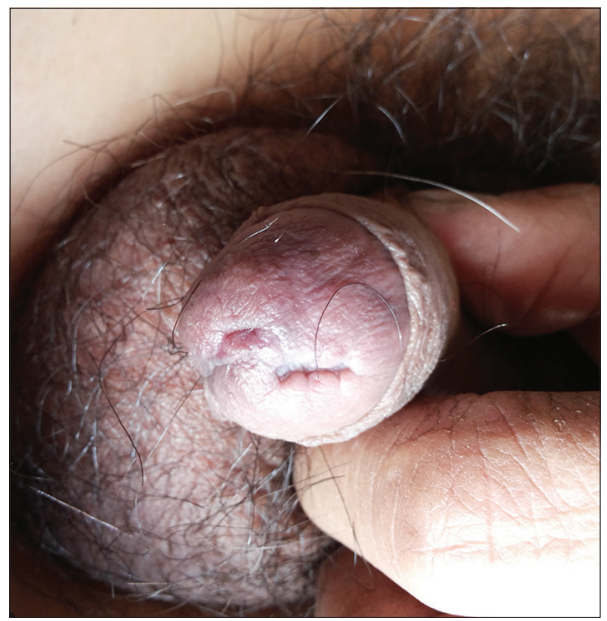

Figure 3: Post treatment scar

more common in $19^{\text {th }}$ century with approximately 161 published cases [1]; it is interesting to observe primary $\mathrm{TB}$ of glans penis in the era of $21^{\text {st }}$ century.
A study on non-venereal genital dermatosis from India did not find any cases of genital TB amongst 50 studied patients, showing its rarity even in TB prevalent country [2]. There are few recent case reports in the literature on penile tuberculosis with various presentations. A 45 year Indian male patient presented with multiple penile ulcer [3]. Similarly, another patient had ulcero-proliferative penile growth [4]. In a tertiary referral hospital of eastern Nepal, we could find similar case after a gap of 15 years [1]. This is also another evidence for its rarity.

TB glans may be either primary or secondary. Primary cases may be acquired during sexual intercourse, circumcision or from infected fomites. Friction induced epithelial breach facilitates bacterial inoculation in otherwise healthy and resistant mucosa [5]. In our case, infected clothing could be the possible source of infection. The secondary form of penile TB may be because of complication of lung or other organ tuberculosis.

Clinically, it may present as superficial ulcer, multiple asymptomatic penile papules or even cauliflower like growth [6,7]. Sometimes only glans penis may be involved as in our case, making diagnosis more difficult. Since many antibiotics also have some anti-tubercular action, there can be temporary partial improvement in the lesion, which further complicates diagnosis like in our patient.

In $\mathrm{TB}$ prevalent countries like Nepal, even positive mantoux test is not specific for the diagnosis of active tuberculosis [8]. Hence, a high degree of suspicion, supportive biopsy and therapeutic trial will be of great help for diagnosing penile TB as in the current case.

\section{CONCLUSION}

Unless the possibility of tuberculosis is not considered for affecting unusual sites, the diagnosis may be missed or delayed. So, in country like ours where the prevalence of tuberculosis is high, we should always suspect tuberculosis in case of chronic non-healing genital ulcers.

\section{REFERENCES}

1. Sah SP, Ashok Raj G, Joshi A. Primary Tuberculosis of the glans penis. Australas J Dermatol. 1999;40:106-7.

2. Puri N, Puri A. A study on non venereal genital dermatoses in north India. Our Dermatol Online. 2012;3:304-7. 
www.odermatol.com

3. Singal A, Pandhi D, Kataria V, Arora VK. Tuberculosis of the glans penis: an important differential diagnosis of genital ulcer disease. Int J STD AIDS. 2017;28:1453-5.

4. Gangalakshmi C, Sankarmahalingam. Tuberculosis of Glans Penis- A Rare Presentation. J Clin Diagn Res. 2016;10:PD05-6.

5. Lal MM, Sekhon GS, Dhall JC. Tuberculosis of the penis. J Indian Med Assoc.1971;56:316-8.

6. Aytekin S, Göktay F, Yasar \&, Ferhatoglu ZA, Güneş P. Penile tuberculosis: A case report. Indian J Dermatol Venereol Leprol 2017;83:357-9.

7. Khan D, Choudhary A, Dutta A, Khan I. Tuberculosis of the glans penis mimicking as carcinoma. Int J Mycobacteriol. 2016;5:341-2.

8. Loh KY. Role of Mantoux test in the diagnosis of tuberculosis. Malays Fam Physician. 2011;6:85-6.

Copyright by Suchana Marahatta, et al. This is an open-access article distributed under the terms of the Creative Commons Attribution License, which permits unrestricted use, distribution, and reproduction in any medium, provided the original author and source are credited.

Source of Support: Nil, Conflict of Interest: None declared. 